\title{
Producão de goma xantana por $X$. Campestris ATCC 13951 utilizando soro de queijo desproteinado
}

\section{Xanthan gum production by $X$. Campestris ATCC 13951 using deproteinated cheese whey}

\section{Producción de goma xantana por X.Campestris ATCC 13951 utilizando suero de queso desproteinizado}

\author{
Jenny Sobenes G.*; Ranulfo M. Alegre \\ Departamento de Engenharia de Alimentos, Universidade Estadual de Campinas (UNICAMP), Cidade Universitaria \\ "Zeferino Vaz", Rua Monteiro Lobato, 80, Zip Codigo:13083-862, Campinas, SP, Brasil. \\ *jennysobenes@gmail.com
}

Fecha Recepción: 07 de diciembre de 2014 Fecha Aceptación: 22 de junio de 2015

\begin{abstract}
Resumo
A goma xantana é um biopolímero microbiano producido pela bactéria Xanthomonas. O presente trabalho teve como objetivo estudar a produção de goma xantana por processo fermentativo utilizando a linhagem X. campestris ATCC 13951 e como fonte de carbono: soro de queijo desproteinado suplementado com extrato de levedura e sulfato de amônia como fontes de nitrogênio; soro de queijo desproteinado suplementado só com extrato de levedura como fonte de nitrogênio e só soro de queijo desproteinado sem suplementos, tempo de fermentação de $72 \mathrm{~h}$ para os três meios. Dos meios em análise aquele constituido apenas por soro de queijo desproteinado, atingiu o maior rendimento com valor de $58 \%$ e a melhor qualidade de goma.
\end{abstract}

Palabras clave: goma xantana, soro de leite, xanthomonas campestris.

\begin{abstract}
Xantan gum is a biopolimer produced by bacteria from the generous Xantomonas. The objective of this work was to study the xantan gum production using the $X$. campestris ATCC 13591 and deproteined cheese whey, deproteined cheese whey supplemented with yeast extract and deproteined cheese whey supplemente with yeast extract and ammonium sulphate as nitrogen source during 72 hours of fermentation. The best result was found when the medium was not supplemented, reaching yield of $58 \%$ and good quality of the gum.
\end{abstract}

Keywords: xanthan gum, milk whey, xanthomonas campestris.

\section{Resumen}

La goma xantana es un biopolímero microbiano producido por la bacteria Xanthomonas. El presente trabajo tuvo como objetivo estudiar la producción de goma xantana por proceso fermentativo utilizando linaje X. campestris ATCC 13951 y como fuente de carbono: suero de queso desproteinizado adicionado de extracto de levadura y sulfato de amonio como fuentes de nitrógeno; suero de queso desproteinizado adicionado solo con extracto de levadura como fuente de nitrógeno y como tercer medio el propio suero de queso desproteinizado; tiempo de fermentación de $72 \mathrm{~h}$ para los tres medios. De los medios 
evaluados aquel constituido únicamente por el propio suero de queso desproteinizado, alcanzó el mayor rendimiento con un valor de $58 \%$ y la mejor calidad de goma.

Palabras-chave: goma xantana, suero de leche, xanthomonas campestris.

\section{Introdução}

Os biopolimeros são macromoléculas formadas por monossacarídeos e derivados ácidos, podendo ser sintetizados por bactérias, fungos e leveduras e devido as suas características reológicas, encontram ampla aplicatividade em processos industriais.

A goma xantana é um biopolimero produzido em processos fermentativos por micro-organismos do gênero Xanthomonas espécie $X$. campestris, sua estrutura consiste em uma cadeia principal de $(1,4) \beta$-D-glicose com estrutura muito parecida a da celulose [13].

A esta cadeia principal de glucano, correntes laterais de trissacarídeos estão ligados alternadamente, através de O-3 (D-glicose da cadeia principal) ao $\mathrm{C} 1$ do primeiro resíduo $\beta$-d-manose. Um grupo de piruvato está ligado às posições 4 e 6 desta unidade de manose terminal, a presença de acido pirúvico representa aproximadamente $60 \%$ da molécula, conferindo a goma muitas das suas propriedades únicas de viscosidade, extraordinária resistência a hidrólise e propriedades de uniformidade física e química. A presença da cadeia lateral na estrutura deste polissacarídeo permite a completa hidratação dele em agua $[4,6]$.

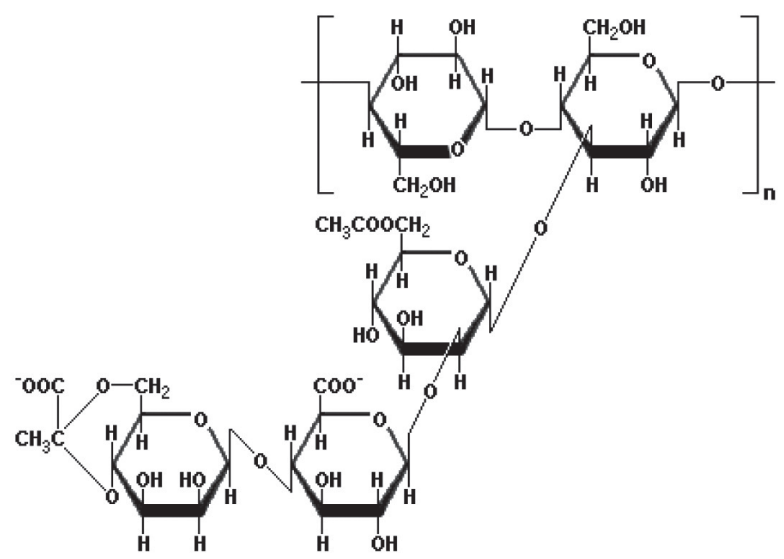

Figura 1. Estrutura química da Goma Xantana Fonte: Nussinovitch A. [6]. (Reproduzida com autorização da NutraSweet Kelco Co.)
Aproximadamente 50000Ton de goma xantana são produzidas anualmente das quais aproximadamente $40 \%$ é utilizado pela industria de alimentos como estabilizante pelas diversas características e vantagens reológicas que apresenta [6,17], ganhando quase um quarto do mercado Norte Americano $[10,16]$.

$\mathrm{Na}$ atualidade a xantana é um dos biopolimeros de maior produção comercial, seus custos de produção são conduzidos pelo rendimento do polímero em relação a quantidade de fonte de carbono necessário, bem como por exigências de processamento $[9,10,16,18]$.

Estudos de otimização do rendimento e produtividade dos processos fermentativos para produção deste polissacarídeo representam na atualidade um constante desafio.

Geralmente a produção de goma xantana é maior quando as bacterias se desenvolvem num meio simples constituido de glicose, sais, fontes de nitrogênio, e melhorada com a adição de pequenas quantidades de ácidos orgánicos [2,15]. Mas atualmente a produção da goma xantana em escala industrial, tenta utilizar fontes de carbono alternativas visto que o uso de glicose e sacarose fazem com que o custo de produção seja elevado. O soro de leite é um dos meios alternativos que apresenta resultados satisfatórios na produção deste polissacarídeo, uma vez que contem elevada quantidade de lactosa e quantidades adequadas de nitrogênio, entre outros fatores propícios para produção de goma xantana por processo fermentativo com $X$. campestris.

O presente trabalho teve como objetivos estudar o processo de produção de goma xantana por linhagem $X$. campestris ATCC 13951, utilizando soro de queijo desproteinado como meio de cultivo, estudando o efeito da concentração de lactose, extrato de levedura e sulfato de amônio na produção de goma xantana.

\section{Parte experimental}

\section{Micro-organismo}

O microorganismo utilizado foi a linhagem de $X$. campestris ATCC 13951, obtida da Coleção de 
Culturas da Fundação Tropical de Pesquisa e Tecnología André Tosello, Campinas - São Paulo.

\section{Meio para manutenção do micro-organismo}

Para o processo de repicagem foi utilizado meio Agar Nutriente do qual após diluição foram adicionados $10 \mathrm{~mL}$ em tubos, os quais foram esterilizados $\left(121^{\circ} \mathrm{C} / 15 \mathrm{~min}\right)$. Os tubos inoculados posteriormente em meio aséptico com o microorganismo X. campestri ATCC 13951 foram mantidos em estufa por $72 \mathrm{~h}$, a temperatura de $30^{\circ} \mathrm{C}$ e conservados posteriormente em refrigeração a $4^{\circ} \mathrm{C}$.

\section{Inóculo}

No preparo do inoculo, frascos de Erlenmeyer de $500 \mathrm{~mL}$ contendo $100 \mathrm{~mL}$ de meio previamente esterilizados $\left(121^{\circ} \mathrm{C} / 15 \mathrm{~min}\right)$ foram inoculados com alça de cultura do micro-organismo em meio semi sólido e incubados em condições de $29^{\circ} \mathrm{C} / 180 \mathrm{rpm} / 24 \mathrm{~h}$.

\section{Meio de cultura e reagentes}

O meio de cultura utilizado foi soro de queijo, este foi adquirido em pó da empresa Alibra cuja composição é mostrada na Tabela 1 , foi reconstituído a diferentes concentrações, e acrescentado de extrato de levedura e sulfato de amônio como fontes de nitrogênio.

O soro a ser utilizado foi desproteinado $(\mathrm{pH} \mathrm{4,3}$ a $93^{\circ} \mathrm{C}$ ) e hidrolisado, acrecentado de extrato de levedura - $3 \mathrm{~g} / \mathrm{L},\left(\mathrm{NH}_{4}\right) \mathrm{SO}_{4}-1,5 \mathrm{~g} / \mathrm{L}, \mathrm{KH}_{2} \mathrm{PO}_{4}$ (20g/L), $\mathrm{MgSO}_{4}(6 \mathrm{~g} / \mathrm{L}), \mathrm{ZnSO}_{4}(2 \mathrm{~g} / \mathrm{L}) \mathrm{pH}$ corrigido a 7,0 con $\mathrm{NaOH} 2 \mathrm{~N}$.

Tabela 1. Composição do meio de cultura utilizado.

\begin{tabular}{lc}
\hline & Meio de cultura \\
\hline Soro de Queijo & Valores médios \\
\hline Aspecto & Pó uniforme sem grumos \\
Sor & Branco a amarelado \\
Sabor & Sabor lácteo, levemente salgado \\
Umidade (\%) & Máx. 3,0 \\
Gordura (\%) & Máx. 1,5 \\
Proteínas (\%) & Min. 10 \\
Acidez (\% Ác. Láctico) & Máx. 2,5 \\
pH (solução 10\%) & 6,0 a 7,0 \\
Teor de cinzas (\%) & Máx. 8,0 \\
Bolores e leveduras & $<50$ \\
Contagem de mesófilos (UFC/g) & $<50000$ \\
Staphylococcus aureus (UFC/g) & $<100$ \\
Coliformes totais (UFC/g) & $<10$ \\
Coliformes Termotolerantes (UFC/g) & $<10$ \\
Salmonella SP & Ausente em 25g \\
\hline
\end{tabular}

Fonte: Alibra 2012.

\section{Produção de goma xantana}

Frascos de Erlenmeyer de $500 \mathrm{~mL}$ contendo $90 \mathrm{~mL}$ de meio foram hidrolisados, inoculados com $10 \mathrm{~mL}$ do pré-inóculo, $\mathrm{pH}$ do meio corrigido a $\mathrm{pH}$ 7. A fermentação dos frascos foi feita em Shaker (TECNAL mod TE 421) $29^{\circ} \mathrm{C} / 180 \mathrm{rpm} / 72 \mathrm{~h}$.

Do meio de fermentação foram retirados $20 \mathrm{~mL}$ de amostra a cada $24 \mathrm{~h}$ para determinação de $\mathrm{pH}$, produção de goma xantana, produção de biomassa e lactose consumida.
Otimização da produção de goma xantana através de Delineamento central composicional rotacional (DCCR)

Para o estudo da influência das variáveis foi utilizado um planejamento experimental 23 completo, com tres pontos centrais (nível 0) e seis pontos axiais (níveis \pm a) totalizando 17 ensaios, onde as variáveis independentes foram: concentração de lactose, concentraçao de extrato de levedura e concentração de sulfato de amônio. 
As respostas estudadas foram: goma xantana produzida (g/L), produção de biomassa (g/L) e lactose consumida ( $\mathrm{g} / \mathrm{L}$ ). Para comprovar o melhor resultado obtido do planejamento, foram feitos ensaios com três repetições.

A Tabela 2 apresenta os valores utilizados para cada uma das variáveis no planejamento.

Tabela 2. Valores utilizados no DCCR para três fatores.

\begin{tabular}{ccccccc}
\hline Variáveis $(\mathrm{g} / \mathrm{L})$ & Código & $-1,68$ & -1 & 0 & 1 & 1,68 \\
\hline Lactose & $\mathrm{X}_{1}$ & 44,00 & 62,00 & 89,00 & 116,00 & 133,00 \\
Ext. Levedura & $\mathrm{X}_{2}$ & 3,00 & 3,81 & 5,00 & 6,19 & 7,00 \\
$\left(\mathrm{NH}_{4}\right)_{2} \mathrm{SO}_{4}$ & $\mathrm{X}_{3}$ & 0,625 & 1,00 & 1,50 & 2,00 & 2,375 \\
\hline
\end{tabular}

\section{Recuperaçaõ da goma xantana do meio} fermentado

A goma produzida foi precipitada com etanol $99,5^{\circ} \mathrm{GL}$ [3], a massa celular foi separada por centrifugação $6.000 \mathrm{rpm}(2.300 \mathrm{~g})$ e a secagem foi feita em estufa a vácuo a $110 \mathrm{mmHg}$ e $60^{\circ} \mathrm{C}$, até peso constante.

\section{Resultados e Discussão}

Produção de goma xantana através de Delineamento composto central rotacional em meio constituído de soro de queijo desproteinado, extrato de levedura e sulfato de amônio

$\mathrm{Na}$ Tabela 3 são mostrados os resultados de produção de goma após $72 \mathrm{~h}$ de fermentação, utilizando sulfato de amônio como fonte adicional de nitrogênio, assim também os resultados de produção de biomassa, os valores de lactose consumida e os valores de $\mathrm{pH}$.

Em uma análise geral dos dados da Tabela $3 \mathrm{em}$ quanto a produção de goma após $72 \mathrm{~h}$, observase que para aqueles ensaios com baixas concentração das fontes de nitrogênio (sulfato de amônio e extrato de levedura) obteve-se maiores valores de produção de goma, ao redor de $18 \pm 1$ (g/L). A goma obtida nestes ensaios apresentou ademais maior textura, foi mais consistente e muito, mas elástica.

Segundo Souw e Demain [14] quando o carbono e o fósforo são nutrientes limitantes, a produção de goma xantana aumenta.

Tabela 3. Produção de goma xantana por $X$. campestris utilizando soro de queijo desproteinado suplementedo com sulfato de amônio; biomassa produzida e lactose consumida (g/L).

\begin{tabular}{cccccccc}
\hline \multirow{2}{*}{ Ensaios } & \multirow{2}{*}{$\begin{array}{c}\text { Lactose } \\
\mathbf{( g / L )}\end{array}$} & $\begin{array}{c}\text { Ext. Lev. } \\
\mathbf{( g / L )}\end{array}$ & $\begin{array}{c}\text { Sulfato } \\
\mathbf{( g / L )}\end{array}$ & $\begin{array}{c}\text { Goma } \\
\mathbf{( g / L )}\end{array}$ & $\begin{array}{c}\text { Biomassa } \\
\mathbf{( g / L )}\end{array}$ & $\begin{array}{c}\text { Lact. consumida } \\
\mathbf{( g / L )}\end{array}$ & $\mathbf{p H}$ \\
\hline 1 & 62 & 3,81 & 1,00 & 17,580 & 5,260 & 47,759 & 6,49 \\
2 & 116 & 3,81 & 1,00 & 18,480 & 6,100 & 73,166 & 7,35 \\
3 & 62 & 6,19 & 1,00 & 18,240 & 5,060 & 47,591 & 6,53 \\
4 & 116 & 6,19 & 1,00 & 18,000 & 7,860 & 71,652 & 7,28 \\
5 & 62 & 3,81 & 2,00 & 17,700 & 2,420 & 51,460 & 6,69 \\
6 & 116 & 3,81 & 2,00 & 17,220 & 7,220 & 68,400 & 7,25 \\
7 & 62 & 6,19 & 2,00 & 13,800 & 6,400 & 47,012 & 6,94 \\
8 & 116 & 6,19 & 2,00 & 13,980 & 7,700 & 65,653 & 7,27 \\
9 & 44 & 5,00 & 1,50 & 13,680 & 4,260 & 40,150 & 6,20 \\
10 & 133 & 5,00 & 1,50 & 11,340 & 7,680 & 78,280 & 7,36 \\
11 & 89 & 3,00 & 1,50 & 17,640 & 5,600 & 59,846 & 6,73 \\
12 & 89 & 7,00 & 1,5 & 12,720 & 8,920 & 50,819 & 7,29 \\
13 & 89 & 5,00 & 0,625 & 17,700 & 6,200 & 62,986 & 6,83 \\
14 & 89 & 5,00 & 2,38 & 12,900 & 8,080 & 53,454 & 7,22 \\
15 & 89 & 5,00 & 1,50 & 12,360 & 7,740 & 49,754 & 7,28 \\
16 & 89 & 5,00 & 1,50 & 12,480 & 8,000 & 53,286 & 7,28 \\
17 & 89 & 5,00 & 1,50 & 12,240 & 7,580 & 52,838 & 7,24 \\
\hline
\end{tabular}

*Tempo de fermentação. 
Após análise estatística do planejamento experimental (DCCR), e segundo o observado na Figura 2 das superficies de resposta, observase que para os três componentes do meio de cultura pode-

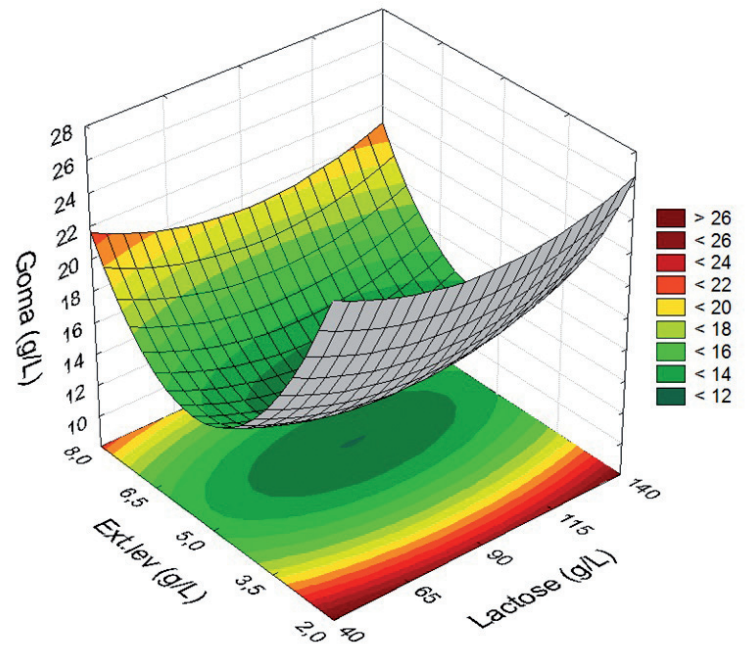

(a) se utilizar concentrações minimas ou máximas para obter boa produção de goma xantana, pelo qual optou-se por utilizar baixas concentrações a fim de reduzir custos de processamento.

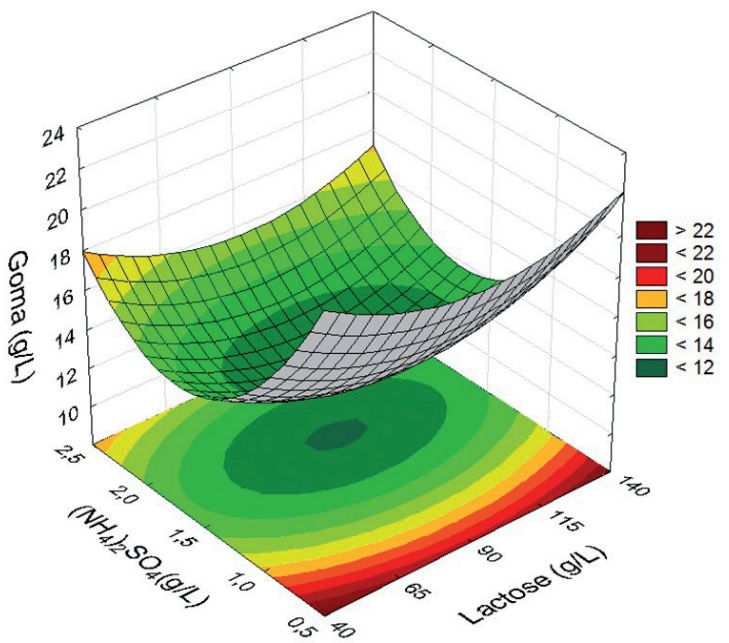

(b)

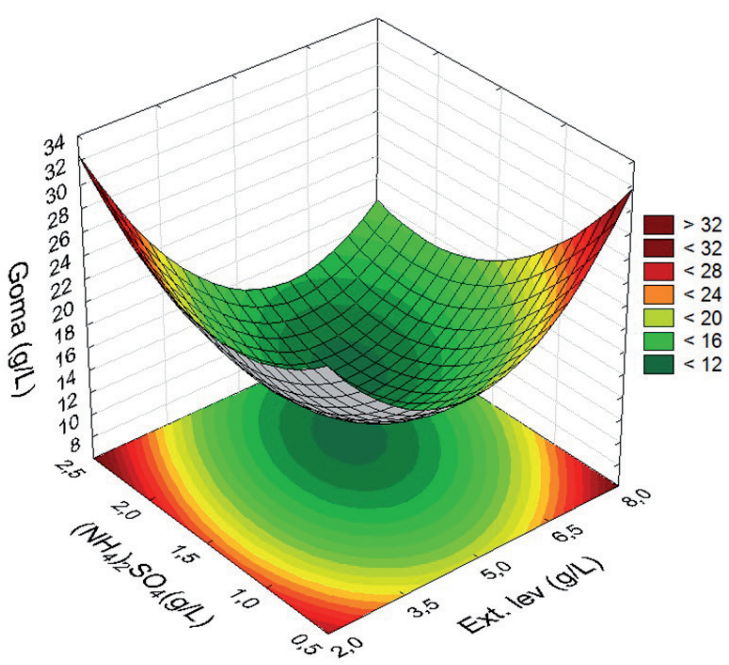

(c)

Figura 2. Superficies de resposta para produção de goma xantana (g/L) em função da concentração de lactose e de extrato de levedura (a), da concentração de lactose e de sulfato de amônio (b) e da concentração de extrato de levedura e de sulfato de amônio (c).

Considerou-se então que a melhor composição do meio para produção de goma, seria o ensaio denominado apartir de agora como A, com as concentrações mais baixas de lactose e extrato de levedura e concentração intermediária das fontes de nitrogênio (44,3 e 1,5g/L). Alguns artigos sobre produção de goma xantana coincidem em sinalar uso de concentrações de entre $40-43 \mathrm{~g} / \mathrm{Kg}$ para a fonte de carbono [1,2,11].

Foram feitas analises da produção de goma xantana, biomassa e lactose consumida a cada 24h como mostrado na Tabela 4.

Após $72 \mathrm{~h}$ de fermentação, a produção de goma no meio com sulfato de amônio apresentó valor de $20,28 \mathrm{~g} / \mathrm{L}$, rendimento de $50 \%$ e produtividade de $0,28 \mathrm{gL}^{-1} \mathrm{~h}^{-1}$.

A concentração da fonte de carbono afeta a eficiência da conversão em polissacarídeos, sendo relatado na literatura que concentrações entre $1-5 \%$, dão o melhor rendimento, enquanto que em concentrações mais altas, o rendimento do produto decresce [8]. 
Tabela 4. Concentração de goma xantana, concentração de biomassa e lactose consumida (g/L) em meio constituido por soro desproteinado, extrato de levedura e sulfato de amônio.

\begin{tabular}{cccc}
\hline Tempo (h) & \multicolumn{3}{c}{ Meio: Soro, Extrato de Levedura e Sulfato de amônio } \\
Biomassa & $\begin{array}{c}\text { Lact. Consumida } \\
\text { (g/L) }\end{array}$ \\
\hline 24 & 5,22 & 2,60 & 15,66 \\
48 & 13,44 & 4,36 & 29,86 \\
72 & 20,28 & 2,64 & 40,47 \\
\hline
\end{tabular}

Produção de goma xantana excluindo do meio de cultivo as fontes adicionais de nitrogênio Baseados nos resultados dos ensaios anteriores onde se obteve boa produção de goma, a baixas concentrações das fontes de nitrogênio, foram realizados testes com meios não suplementados com sulfato de amônio nem extrato de levedura.

A Tabela 5, mostra os resultados de produção de goma xantana, produção de biomassa, assim como os valores de lactose consumida e lactose remanescente após $72 \mathrm{~h}$ de fermentação para o meio contendo soro desproteinado suplementado com extrato de levedura. Os ensaios 4 e 5 tiveram os maiores resultados de produção de goma, com 23,28g/L, rendimentos de $29 \%$ e $27 \%$, respectivamente, e produtividade de $0,32 \mathrm{gL}^{-1} \mathrm{~h}^{-1}$, no entanto, a quantidade de lactose remanescente no meio foi bastante alto. $O$ ensaio 1 pela sua ves, reportou produção de goma de 18,72g/L, rendimento de $46 \%$ e elevado consumo de lactose no meio, o qual deixa um resíduo menos poluidor.

Tabela 5. Produção de goma, produção de biomassa e lactose consumida (g/L) por $X$. campestris utilizando como meio soro desproteinado suplementado com extrato de levedura.

\begin{tabular}{|c|c|c|c|c|c|c|}
\hline \multirow[b]{2}{*}{ Ensaios } & \multirow[b]{2}{*}{$\begin{array}{l}\text { Lact. } \\
\text { (g/L) }\end{array}$} & \multirow[b]{2}{*}{$\begin{array}{c}\text { Ext. Lev. } \\
\text { (g/L) }\end{array}$} & \multicolumn{4}{|c|}{$72 h^{*}$} \\
\hline & & & $\begin{array}{c}\text { Goma } \\
\text { (g/L) }\end{array}$ & $\begin{array}{c}\text { Biomas. } \\
\text { (g/L) }\end{array}$ & $\begin{array}{l}\text { Lact. Cons. } \\
\qquad(\mathrm{g} / \mathrm{L})\end{array}$ & $\begin{array}{l}\text { Lact. Rem. } \\
\qquad(\mathrm{g} / \mathrm{L})\end{array}$ \\
\hline 1 & 44 & 3 & 18,72 & 0,30 & 40,36 & 3,64 \\
\hline 2 & 62 & 3 & 18,84 & 0,72 & 49,96 & 12,04 \\
\hline 3 & 89 & 3 & 22,56 & 1,68 & 62,80 & 26,20 \\
\hline 4 & 116 & 3 & 23,28 & 3,60 & 80,50 & 35,50 \\
\hline 5 & 133 & 3 & 23,28 & 5,70 & 86,21 & 46,79 \\
\hline
\end{tabular}

*Tempo de fermentação.

A Tabela 6 mostra os resultados obtidos utilizando meio constituído apenas por soro de queijo desproteinado, observa-se que independente da concentração de lactose utilizada para produção de goma, foram obtidas cerca de $20 \mathrm{~g} / \mathrm{L}$ após $72 \mathrm{~h}$ de fermentação valor próximo aos obtidos nos meios suplementados (Tabela 4). A produtividade obtida foi de $0,27 \mathrm{gL}^{-1} \mathrm{~h}^{-1}$. Em termos de rendimento o ensaio 1 obteve maior valor $58 \%$. Pode-se concluir que a suplementação do soro é desnecessária, não havendo também a necessidade de concentrar o soro, uma vez que em concentrações altas de lactose não se obteve maiores produções de goma e a lactose remanescente no meio também é alta. Assim, a utilização de baixa concentração de lactose, além dos benefícios econômicos, traz também o benefício ao meio ambiente, visto ser o efluente menos poluidor. 
Tabela 6. Produção de goma, produção de biomassa e lactose consumida (g/L) por $X$. campestris meio constituído apenas por soro de queijo desproteinado.

\begin{tabular}{cccccc}
\hline & & \multicolumn{3}{c}{$\mathbf{7 2 h}^{*}$} \\
\cline { 3 - 6 } Ensaios & Lact. & $\begin{array}{c}\text { Goma } \\
\mathbf{( g / L )}\end{array}$ & $\begin{array}{c}\text { Biomas. } \\
\mathbf{( g / L )}\end{array}$ & $\begin{array}{c}\text { Lact. Cons. } \\
\mathbf{( g / L} / \mathbf{L})\end{array}$ & $\begin{array}{c}\text { Lact. Rem. } \\
\text { (g/L) }\end{array}$ \\
\hline 1 & 44 & 19,68 & 0,18 & 33,89 & 10,11 \\
2 & 62 & 19,80 & 0,18 & 47,10 & 14,90 \\
3 & 89 & 19,68 & 0,66 & 61,61 & 27,39 \\
4 & 116 & 19,68 & 1,86 & 80,80 & 35,20 \\
5 & 133 & 19,44 & 3,78 & 86,46 & 46,54 \\
\hline
\end{tabular}

*Tempo de fermentação.

A Tabela 7 resume os resultados de produção de goma, produção de biomassa e lactose consumida, obtidos nos ensaios A (soro de queijo desproteinado suplementado com extrato de levedura e sulfato de amônio), B (soro de queijo desproteinado suplementado com extrato de levedura) e $\mathrm{C}$ (soro de queijo desproteinado sem suplementação), a produção de goma em $72 \mathrm{~h}$ de fermentação para cada ensaio foi de $20,28 \mathrm{~g} / \mathrm{L}, 18,72 \mathrm{~g} / \mathrm{L}$ e $19,68 \mathrm{~g} / \mathrm{L}$ respectivamente, com produtividades de $0,28 \mathrm{gL}^{-1} \mathrm{~h}-1,0,26 \mathrm{gL}^{-1} \mathrm{~h}^{-1}$ e $0,27 \mathrm{gL}^{-1} \mathrm{~h}^{-1}$.

A concentração do ensaio $A$ foi superior em $1,56 \mathrm{~g} / \mathrm{L}$ à obtida no ensaio $B$ após $72 \mathrm{~h}$, sendo este o melhor resultado obtido, o que não se esperava visto que o meio A teve suplementação de fontes de nitrogênio. Baixo teor de nitrogênio no meio é favorável na produção de polissacarídeos [7].

Nos ensaios B e C a produção de biomassa foi muito baixa mesmo nas diluções feitas no meio. Enquanto ao consumo de lactose o ensaio $\mathrm{C}$ apresentou o menor valor após $72 \mathrm{~h}$, mas a produção de goma teve o maior rendimento atingindo valor de $58 \%$, sendo o maior rendimento de entre os três ensaios em análise. Este mesmo ensaio após $48 \mathrm{~h}$ de fermentação, já tinha produzido cerca de $3 \mathrm{~g} / \mathrm{L}$ de goma mais que os outros, como pode-se observar na Tabela 7 e na Figura 3, e além disso apresentou boa qualidade de goma com rendimento de $55 \%$.

Tabela 7. Produção de goma, produção de biomassa e lactose consumida (g/L) por $X$. campestris em soro de queijo desproteinado suplementado com extrato de levedura e sulfato de amônio, soro de queijo desproteinado suplementado com extrato de levedura e soro de queijo desproteinado sem suplementação.

\begin{tabular}{ccccccccccc}
\hline \multirow{2}{*}{ Ensaios } & \multicolumn{3}{c}{$\mathbf{2 4 h}$} & \multicolumn{9}{c}{$\mathbf{4 8 h}$} & \multicolumn{3}{c}{$\mathbf{7 2 h}$} \\
\cline { 2 - 10 } & Goma & Biomas. & $\begin{array}{c}\text { Lact. } \\
\text { Cons. }\end{array}$ & Goma & Biomas. & Lact. & Cons. & Goma & Biomas. & $\begin{array}{c}\text { Lact. } \\
\text { Cons. }\end{array}$ \\
\cline { 2 - 10 } & $\mathbf{( g / L )}$ & $\mathbf{( g / L )}$ & $\mathbf{( g / L )}$ & $\mathbf{( g / L )}$ & $\mathbf{( g / L )}$ & $\mathbf{( g / L )}$ & $\mathbf{( g / L )}$ & $\mathbf{( g / L )}$ & $\mathbf{( g / L )}$ \\
\hline A & 5,22 & 2,60 & 15,66 & 13,44 & 4,36 & 29,86 & 20,28 & 2,64 & 40,47 \\
B & 4,20 & 0,78 & 14,99 & 14,04 & 0,90 & 30,03 & 18,72 & 0,30 & 40,36 \\
C & 6,48 & 0,48 & 16,66 & 17,88 & 0,96 & 32,66 & 19,68 & 0,18 & 33,89 \\
\hline
\end{tabular}

Ensaio $A$ = soro desproteinado (lactose $44 \mathrm{~g} / \mathrm{L}$ ), extrato de levedura (3g/L) e sulfato de amônio (1,5g/L);

Ensaio $B=$ soro desproteinado (lactose $44 \mathrm{~g} / \mathrm{L}$ ) e extrato de levedura $(3 \mathrm{~g} / \mathrm{L})$;

Ensaio $\mathrm{C}=$ soro desproteinado (lactose $44 \mathrm{~g} / \mathrm{L}$ ).

A Figura 4 relaciona a produção de goma xantana com o tempo de fermentação, mostrando que para os três ensaios em análise, não houve grandes diferenças na produção da goma após $72 \mathrm{~h}$ de fermentação.

No ensaio A a produção de goma em $48 \mathrm{~h}$ de fermentação atingiu $90 \%$ da concentração atingida em $72 \mathrm{~h}$ e ao redor de $3,5 \mathrm{~g} / \mathrm{L}$ a mais de goma que nos outros ensaios, mas mesmo assim, não foi o melhor meio em termos de custos pois ele foi suplementado com fontes adicionais de nitrogênio. $\mathrm{O}$ ensaio $\mathrm{C}$ não teve suplementação nenhuma $\mathrm{e}$ mesmo assim em 48h de fermentação foram obtidos bons resultados, após $72 \mathrm{~h}$ este ensaio atingiu produção de goma de 19,68 (g/L) o maior rendimento com $58 \%$ e produtividade de $0,27 \mathrm{gL}^{-1} \mathrm{~h}^{-1}$, além de boa qualidade de goma. Nitschke et al. [5]; no seu estudo utilizando soro de leite para produção de 
biopolímeros pela cepa Xanthomonas campestris $\mathrm{C}_{7} \mathrm{~L}$ obteve produção de $14,70 \mathrm{~g} / \mathrm{L}$ de goma xantana a $200 \mathrm{rpm} / 28^{\circ} \mathrm{C} / 72 \mathrm{~h}$; entanto que Silva e
Treichel [12], obtiveram produção de 25,40g/L de goma xantana pela cepa Xanthomonas campestris 1230 , a $180 \mathrm{rpm} / 28^{\circ} \mathrm{C} / 72 \mathrm{~h}$.

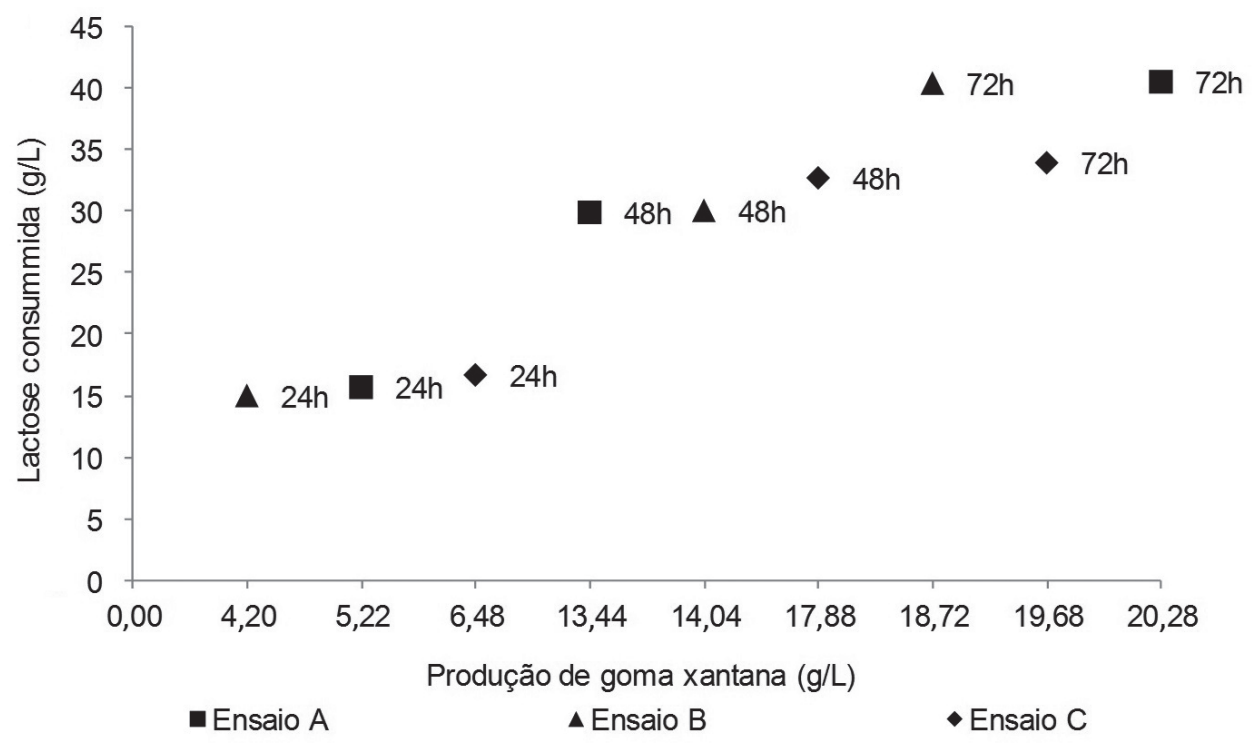

Figura 3. Lactose consumida ( $\mathrm{g} / \mathrm{L})$ vs Produção de goma xantana $(\mathrm{g} / \mathrm{L})$ nos meios soro desproteinado suplementado com extrato de levedura e sulfato de amônio (A); soro desproteinado suplementado com extrato de levedura (B) e soro desproteinado (C).

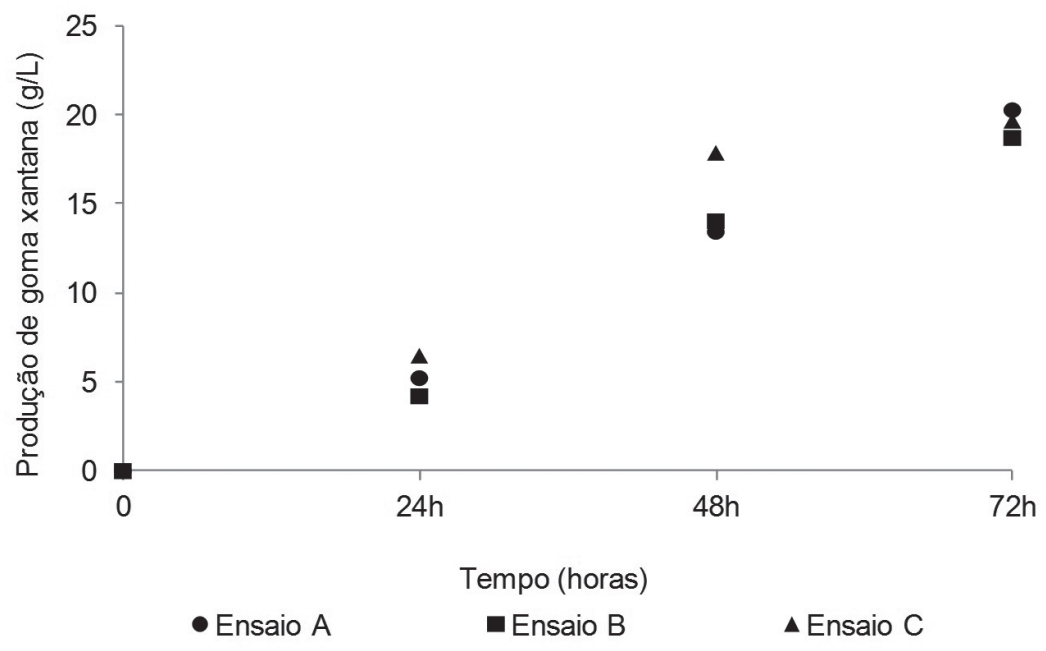

Figura 4. Produção de goma xantana por $X$. campestris nos meios soro desproteinado suplementado com extrato de levedura e sulfato de amônio (A); soro desproteinado suplementado com extrato de levedura (B) e soro desproteinado (C). 


\section{Conclusões}

A produção de goma xantana por $X$. campestris ATCC 13951, utilizando soro de queijo desproteinado e hidrolisado, não necessitou de suplementos de extrato de levedura e sulfato de amônio, porque o próprio soro supriu todos os nutrientes necessários à bactéria, inclusive nitrogênio.

A utilização de soro de queijo concentrado como meio, não aumentou a produção de goma xantana, pelo contrário gerou na maioria dos casos, valores baixos de produção de goma, diminuição pouco acentuada do $\mathrm{pH}$ e elevadas quantidades de lactose no meio ao final do processo.

Embora a concentração de goma xantana obtida a partir de soro de queijo não seja tão alta quanto às gomas obtidas utilizando fontes de carbono convencionais, este processo torna-se atraente porque o soro de queijo é um subproduto de baixo valor agregado e a goma xantana tem larga aplicação industrial em alimentos.

\section{Referências bibliográficas}

[1] De Vuyst L, Vermeire A. Use of industrial medium components for xanthan production by Xanthomonas campestris NRRL-B-1459. Appl Microbiol Biotechnol. 1994;42(2/3):18791.

[2] Funahashi $\mathrm{H}$, Yoshida T, Taguchi H. Effect of glucose concentrations on xanthan gum production by xanthomonas campestris. J. Ferment. Technol. 1987;65(5):603-6.

[3] García Ochoa F, Santos VE, Casas JA, Gómez E. Xanthan gum: production, recovery, and properties. Biotechnology Advances. 2000;18(7):549-79.

[4] Jansson PE, Kenne L, Lindberg B. Structure of the extracellular polysaccharide from xanthomonas campestris. Carbohydr Res. 1975;45(1):275-82.

[5] Nitschke M, Rodrigues V, Schinatto LF. Formulação de meios de cultivo a base de soro de leite para a produção de goma xantana por $X$. campestris C7L1. Ciênc. Tecnol. Aliment. 2001;21(1):82-5.

[6] Nussinovitch A. Hydrocolloid applications: gum technology in the food and other industries. U.S.A: Blackie Academic \& Professional; 1997.

[7] Palaniraj A, Jayaraman V. Production, recovery and applications of xanthan gum by Xanthomonas campestris. J. Food Eng. 2011;106(1):1-12.

[8] Papagianni M, Psomas SK, Batsilas L, Paras SV, Kyriakidis DA, Liakopoulou-Kyriakides M. Xanthan production by Xanthomonas campestris in batch cultures. Process Biochemistry. 2001;37(1):73-80.

[9] Rehm BHA. Bacterial polymers: biosynthesis, modifications and applications. Nature Reviews Microbiology. 2010;8(8):578-92.

[10] Rosalam S, England R. Review of xanthan gum production from unmodified starches by Xanthomonas comprestris sp. Enzyme and Microbial Technology. 2006;39(2):197-207.

[11] Savvides AL, Katsifas EA, Hatzinikolaou DG. Xanthan production using whey permeate medium. World J Microbiol Biotechnol. 2012;28:2759-64.

[12] Silva MF, Treichel H. Aproveitamento de soro de leite para produção de polissacsrídeos. Vivências - Erechim. 2006;1(3):1-4.

[13] Sloneker JH, Jeanes A. Exocellular bacterial polysaccharide from Xanthomonas campestris NRRL B-1459: Part I. Constitution. Can. J. Chem. 2013;40(11):2066-71.

[14] Souw P, Demain AL. Nutritional Studies on Xanthan Production by Xanthomonas campestris NRRL B1459. Applied and Environmental Microbiology.1979;37(6):1186-92.

[15] Sutherland IW. Biotechnology of Microbial Polysaccharides in Food. In: Food Biotechnology. Shetty K, Paliyath G, Pometto A, Levin RE. Editores. CRC Press; 2005.

[16] Waites MJ. Industrial microbiology: an introduction. U.S.A: Blackwell Science; 2001.

[17] Whistler RL, Bemiller JN. Industrial gums: polysaccharides and their derivatives. 3rd ed. U.S.A: Academic Press; 1993.

[18] Wyatt NB, Liberatore MW. Rheology and viscosity scaling of the polyelectrolyte xanthan gum. J Appl Polym Sci. 2009;114(6):407684. 